\title{
Small quantities of carotenoid-rich tropical green leafy vegetables indigenous to Africa maintain vitamin A status in Mongolian gerbils (Meriones unguiculatus)
}

\author{
Richard A. Ejoh ${ }^{1,2}$, Joseph T. Dever ${ }^{1}$, Jordan P. Mills ${ }^{1}$ and Sherry A. Tanumihardjo ${ }^{1}$ \\ ${ }^{1}$ Department of Nutritional Sciences, University of Wisconsin-Madison, 1415 Linden Drive, Madison, WI 53706, USA \\ ${ }^{2}$ Department of Food Science and Nutrition, National School of Agro-Industrial Sciences, University of Ngaoundere, Box 455, \\ Ngaoundere, Cameroon
}

(Received 8 May 2009 - Revised 23 November 2009 - Accepted 26 November 2009 - First published online 23 April 2010)

\begin{abstract}
Leafy vegetables are important sources of provitamin A carotenoids. Information on their ability to provide vitamin A is often misleading because of the methodology used to assess bioefficacy. Mongolian gerbils were used to evaluate the bioefficacy of provitamin A carotenoids in tropical leafy vegetables (i.e. Solanum nigrum, Moringa oleifera, Vernonia calvoana and Hibiscus cannabinus) that are indigenous to Africa. Gerbils ( $n$ 67) were vitamin A-depleted for 5 weeks. After a baseline kill $(n$ 7), the gerbils were weight-matched and assigned to six treatment groups ( $n$ 10; four vegetable groups; negative and positive controls). For 4 weeks, the treatments included $35 \mathrm{nmol}$ vitamin A (theoretical concentrations based on $100 \%$ bioefficacy) in the form of vegetables or retinyl acetate. In addition to their diets, the control and vegetable groups received daily doses of oil, while the vitamin A group received retinyl acetate in oil matched to prior day intake. Serum and livers were analysed for vitamin A using HPLC. Serum retinol concentrations did not differ among groups, but total liver vitamin A of the vitamin A and vegetable groups were higher than that of the negative control group $(P<0 \cdot 0001)$. Liver $\beta$-carotene $15,15^{\prime}$-monooxygenase-1 expression levels were determined for two vegetable groups and were similar to the positive and negative controls. Conversion factors for the different leafy vegetables were between 1.9 and $2.3 \mu \mathrm{g} \beta$-carotene equivalents to $1 \mu \mathrm{g}$ retinol. Small quantities of these vegetables maintained vitamin A status in gerbils through efficient bioconversion of $\beta$-carotene to retinol.
\end{abstract}

Tropical leafy vegetables: Vitamin A status: Provitamin A carotenoids: Bioconversion factors: Bioefficacy

Micronutrient malnutrition is still a problem of unacceptable proportions in developing countries. Vitamin A deficiency is known to be one of the most widespread nutritional deficiencies in the world today ${ }^{(1-3)}$. Vitamin A deficiency leads to impaired cellular functioning because it has an important role in numerous physiological processes in human subjects. The World Health Organization Micronutrient Deficiency Information System indicates that over ninety countries have a public health problem with regard to clinical or sub-clinical vitamin A deficiency ${ }^{(4)}$. Over 3 million blind children in the world can be traced to vitamin A deficiency. This situation weighs heavily on 100-150 million preschool children and about 7 million pregnant women ${ }^{(2)}$. Because this micronutrient deficiency disproportionately affects children and women during their reproductive years, it hinders the development of human potential and social and economic development.

Poor people in tropical Africa obtain most of their nutrients from plant foods, which are cheaper and more accessible than animal foods ${ }^{(5)}$. As its cornerstone, the FAO has supported the increased production and consumption of vitamin A-rich foods as a sustainable solution to this micronutrient deficiency. Leafy vegetables have been an integral part of the diet of the populations of all socioeconomic classes in tropical Africa. In addition to serving as an important source of minerals, they are also rich in provitamin A carotenoids particularly $\beta$-carotene ${ }^{(6-10)}$. The bioefficacy of provitamin A carotenoids from leafy vegetables is not well understood and as such, enormous efforts have been made only on vitamin A-rich staple foods as a sustainable means to alleviate vitamin A deficiency ${ }^{(11,12)}$. It is therefore essential to assess the bioefficacy of carotenoids from commonly used tropical leafy vegetables.

To assess if provitamin A carotenoids positively contribute to vitamin A status, several factors have to be considered. The absorption and bioconversion of carotenoids are thought to be primarily influenced by the food matrix, presence and types of fat and amount of fibre among others ${ }^{(13-18)}$. Bioconversion is tightly regulated and dependent on the vitamin A status and the amount administered in the meal ${ }^{(15)}$. The Mongolian gerbil is an appropriate animal model to demonstrate bioconversion of carotenoids to vitamin A and 
permits direct measurement of liver vitamin $\mathrm{A}^{(19)}$. It is essential to identify provitamin A dense leafy vegetables among the commonly consumed foods in areas of vitamin A deficiency that possess optimal carotenoid retention and are bioefficacious $^{(20)}$. The present study determined the bioefficacy of provitamin A carotenoids from tropical leafy vegetables indigenous to Africa using gerbils as a model. Furthermore, the expression of $\beta$-carotene $15,15^{\prime}$-monooxygenase-1 (BCMO1) was evaluated in liver from gerbils fed vegetables, vitamin A supplements or oil control.

\section{Materials and methods}

\section{Animals and procedures}

Male Mongolian gerbils ( $40 \mathrm{~d}$ old, $n$ 67) were obtained from Charles River Laboratories (Kingston, NY, USA). Upon arrival, the gerbils were housed individually in plastic cages and immediately placed on a vitamin A- and carotenoid-free feed (Harlan-Teklad, Madison, WI, USA). The animals were given free access to feed and water. Room temperature and humidity were kept constant at $23^{\circ} \mathrm{C}$ and $40 \%$, respectively, with a $12 \mathrm{~h}$ light-dark cycle. The gerbils were weighed daily to monitor health for the first 2 weeks and then every $3 \mathrm{~d}$ until killed. During a 5-week vitamin A-depletion phase, gerbils were acclimated to oral dosing by administering $40 \mu \mathrm{l}$ cottonseed oil every $3 \mathrm{~d}$, using a $100 \mu \mathrm{l}$ Gilson positive displacement pipette (Rainin Instruments, Woburn, MA, USA).

After the 5-week depletion phase, the gerbils from the baseline group ( $n$ 7) were exsanguinated while under isoflurane anaesthesia to establish pretreatment serum and liver vitamin A concentrations. The remaining gerbils were weight-matched and allocated to six treatment groups ( $n$ 10) as described later. After the 4-week treatment period, the remaining gerbils were exsanguinated. Blood samples were centrifuged at $2200 \mathrm{~g}$ for $15 \mathrm{~min}$ in BD Vacutainer Gel and Clot Activator tubes (Becton Dickinson, Franklin Lakes, NJ,
USA) for serum isolation. Livers were removed and stored at $-70^{\circ} \mathrm{C}$. All animal handling procedures were approved by the College of Agriculture and Life Sciences Animal Care and Use Committee of the University of Wisconsin-Madison.

\section{Leafy vegetables and diets}

Leafy vegetables were obtained from different markets in Ngaoundéré (Cameroon, Africa) and immediately transported to the biochemistry laboratory at the University of Ngaoundéré for different preparation steps. The vegetable samples were either boiled (Vernonia calvoana) or used raw (Solanum nigrum, Moringa oleifera and Hibiscus cannabinus) for the determination of proximate composition. Samples for the bioefficacy studies were oven-dried $\left(40^{\circ} \mathrm{C}\right)$ and stored at $-2^{\circ} \mathrm{C}$ in airtight containers for $10 \mathrm{~d}$ before being transported to Madison, WI, USA. Upon arrival, the samples were stored cool $\left(-2^{\circ} \mathrm{C}\right)$ for a month and ground into powder before use for the animal study and carotenoid determination. The diets for the present study were designed to have similar protein and energy content (Table 1). The diets administered were made to contain $17 \%$ protein, $63 \%$ carbohydrate and $6 \%$ fat, providing about $16000 \mathrm{~kJ}(3800 \mathrm{kcal}) / \mathrm{kg}$. For the vitamin A-depletion phase, gerbils were fed a powdered, vitamin A- and carotenoid-free diet based on the AIN-93 rodent $\operatorname{diet}^{(21)}$. During the treatment phase, gerbils were given one of six treatments: vitamin A-free basal diet and daily oral cottonseed oil doses; four customised diets with added powdered leafy vegetables and daily oral cottonseed oil doses; the vitamin A-free basal diet plus daily oral doses of vitamin A (retinyl acetate) dissolved in cottonseed oil. The vitamin A group received $100 \%$ of the theoretical vitamin A that the vegetable groups ate the day before. The amounts of vegetable added were calculated on the basis that theoretically each mol $\beta$-carotene, 13-cis- $\beta$-carotene and 9-cis- $\beta$-carotene result in $2 \mathrm{~mol}$ retinol upon central cleavage, and $1 \mathrm{~mol} \alpha$-carotene provides $1 \mathrm{~mol}$

Table 1. Composition of gerbil diets used to determine the bioefficacy of green leafy vegetables common in Africa

\begin{tabular}{|c|c|c|c|c|c|}
\hline & $\begin{array}{l}\text { Vitamin A-free diet } \\
(\mathrm{g} / \mathrm{kg} \text { feed })\end{array}$ & $\begin{array}{l}\text { Solanum nigrum diet } \\
(\mathrm{g} / \mathrm{kg} \text { feed })\end{array}$ & $\begin{array}{c}\text { Moringa oleifera diet } \\
(\mathrm{g} / \mathrm{kg} \text { feed })\end{array}$ & $\begin{array}{c}\text { Vernonia calvoana diet } \\
(\mathrm{g} / \mathrm{kg} \text { feed })\end{array}$ & $\begin{array}{l}\text { Hibiscus cannabinus diet } \\
(\mathrm{g} / \mathrm{kg} \text { feed })\end{array}$ \\
\hline Casein (vitamin A free) & 200 & $196 \cdot 3$ & $195 \cdot 7$ & $183 \cdot 1$ & $195 \cdot 1$ \\
\hline L-Cystine & 3.0 & 2.9 & 2.9 & $2 \cdot 8$ & 2.9 \\
\hline Sucrose & $360 \cdot 5$ & 353.8 & $352 \cdot 8$ & $330 \cdot 1$ & $351 \cdot 7$ \\
\hline Maltodextrin & 120 & $117 \cdot 8$ & $117 \cdot 4$ & $109 \cdot 9$ & $117 \cdot 1$ \\
\hline Maize starch & 150 & $147 \cdot 2$ & $146 \cdot 8$ & $137 \cdot 3$ & $146 \cdot 3$ \\
\hline Cottonseed oil & 60 & 60 & 60 & 60 & 60 \\
\hline Cellulose & 60 & $58 \cdot 9$ & 58.7 & 54.9 & 58.5 \\
\hline Mineral mix ${ }^{*}$ & 35 & 34.4 & $34 \cdot 3$ & $32 \cdot 1$ & $34 \cdot 2$ \\
\hline Magnesium oxide & $1 \cdot 8$ & 1.7 & 1.7 & 1.60 & 1.7 \\
\hline Calcium phosphate (dibasic) & $2 \cdot 0$ & $2 \cdot 0$ & $2 \cdot 0$ & $1 \cdot 8$ & $2 \cdot 0$ \\
\hline Vitamin mix $†$ & $5 \cdot 0$ & 4.9 & 4.9 & 4.6 & 4.9 \\
\hline Vitamin E acetate & 0.2 & 0.2 & 0.2 & 0.2 & 0.2 \\
\hline Vitamin $D_{3}$ & 0.004 & 0.004 & 0.004 & 0.004 & 0.004 \\
\hline Choline bitartrate & $2 \cdot 5$ & 2.5 & 2.5 & $2 \cdot 3$ & $2 \cdot 4$ \\
\hline S. nigrum & 0 & $18 \cdot 6$ & 0 & 0 & 0 \\
\hline M. oleifera & 0 & 0 & 21.4 & 0 & 0 \\
\hline V. calvoana & 0 & 0 & 0 & 84.4 & 0 \\
\hline H. cannabinus & 0 & 0 & 0 & 0 & 24.4 \\
\hline
\end{tabular}

${ }^{*}$ AIN-93M-MX (21).

†The vitamin mix provided the following ( $\mathrm{mg} / \mathrm{kg}$ feed): biotin, 0.4; calcium pantothenate, $66 \cdot 1$; folic acid, 2; inositol, 110.1; menadione, 49.6; niacin, 99.1; $p$-aminobenzoic acid, 110.1; pyridoxine-HCl, 22; riboflavin, 22; thiamin- $\mathrm{HCl}, 22$; vitamin $\mathrm{B}_{12}(0.1 \%$ in mannitol), 29.7; ascorbic acid (97.5\%). 
retinol. The diets were prepared using $S$. nigrum, M. oleifera, $V$. calvoana and $H$. cannabinus at $1.86,2.14,8.44$ and $2.44 \%$, respectively, to make up the $35 \mathrm{nmol}$ of daily theoretical vitamin A intake of the gerbils assuming a daily food intake of $6 \mathrm{~g}(5.83 \mathrm{nmol}$ vitamin $\mathrm{A} / \mathrm{g}$ diet $)$. Feeds and vitamin $\mathrm{A}$ in oil were stored at 2 and $-18^{\circ} \mathrm{C}$, respectively, during the study. The vitamin A in oil solution contained $0.897 \mathrm{nmol} /$ $\mu$ l. Feed consumption was measured daily on a subset of the vegetable-treated groups.

\section{Analysis and diet composition}

In order to equalise the diets for energy and protein, vegetable samples were first analysed for proximate composition using Association of Official Agricultural Chemists' methods ${ }^{(22)}$. A slight modification of the procedure described by Howe \& Tanumihardjo ${ }^{(23)}$ was adopted for quantification of carotenoids in the vegetables and feeds.

Carotenoids were released from dried, powdered vegetables $(0.1 \mathrm{~g})$ or diets $(0.6 \mathrm{~g})$ by heating at $85^{\circ} \mathrm{C}$ for $5 \mathrm{~min}$ in ethanol with butylated hydroxytoluene $(0.1 \% \mathrm{w} / \mathrm{v})$ followed by saponification with $400 \mu \mathrm{l} \mathrm{KOH} \mathrm{(80 \%} \mathrm{in} \mathrm{water).} \mathrm{The} \mathrm{suspension}$ was mixed by vortex for $20 \mathrm{~s}$ and placed in a water-bath $\left(85^{\circ} \mathrm{C}\right)$ for $10 \mathrm{~min}$. The reaction was halted by placing in ice and mixing after introducing $3 \mathrm{ml}$ deionised water before extraction with hexanes (four times). The combined extracts were dried under Ar, reconstituted in $1 \mathrm{ml} \mathrm{50:50} \mathrm{methanol-}$ dichloroethane and $25 \mu \mathrm{l}$ was injected onto a Waters HPLC system (Milford, MA, USA). This consisted of a C30 YMC $^{\mathrm{TM}}$ carotenoid column $(4.6 \times 250 \mathrm{~mm}, 3 \mu \mathrm{m}), 1525$ binary HPLC pump, 717plus autosampler and a 996 photodiode array detector. The HPLC solvent gradient included methanol-water $(92: 8, \mathrm{v} / \mathrm{v})$ with $10 \mathrm{~mm}$-ammonium acetate (solvent A) and $100 \%$ methyltertiary-butyl diethyl ether (solvent B). Samples were analysed at $1 \mathrm{ml} / \mathrm{min}$ starting with $70 \%$ solvent $\mathrm{A}$ and transitioning to $40 \%$ solvent $\mathrm{A}$ within $30 \mathrm{~min}$. $\beta$-Carotene (including all-trans, 13-cis and 9-cis) and $\alpha$-carotene were identified and quantified using HPLCpurified standards. Concentrations of standards were determined spectrophotometrically using their respective extinction coefficients $\left(E_{1 \mathrm{~cm}}^{1 \%}\right)$. Chromatograms were generated at $450 \mathrm{~nm}$.

\section{Sample preparation and HPLC analyses}

All analyses were performed under gold fluorescent lights to prevent carotenoid photooxidation and isomerisation. Serum retinol analysis was done using a modified procedure ${ }^{(24)}$. Samples were thawed and $200 \mu \mathrm{l}$ was pipetted into a glass tube along with $50 \mu \mathrm{l}$ internal standard (retinyl acetate) to determine the extraction efficiency. Ethanol $(250 \mu \mathrm{l})$ was added to denature proteins, followed by mixing by vortex (15 s). Extraction then proceeded thrice with $300 \mu l$ hexanes and brief centrifugation at $1380 \mathrm{~g}$. The organic layers were pooled and dried under Ar. The dried samples were reconstituted with $50 \mu 1$ 75:25 (v/v) methanol-dichloroethane, mixed for $30 \mathrm{~s}$, and $30 \mu \mathrm{l}$ was injected into the HPLC system described earlier. A Waters Resolve ${ }^{\mathrm{TM}}, 5-\mu \mathrm{m}$ spherical C18 column $(3.9 \times 150 \mathrm{~mm})$ was used and absorbance was monitored at $325 \mathrm{~nm}$. A mobile phase of 90:10 methanolwater with $500 \mu \mathrm{l}$ triethylamine/l was run isocratically at
$1 \mathrm{ml} / \mathrm{min}$. HPLC-purified retinol was used to quantify the retinol in the samples. All the liver samples were analysed for retinol and retinyl esters ${ }^{(25)}$ and a subset of livers ( $n 6$ from both control groups and two vegetable groups (i.e. $S$. nigrum and $V$. calvoana)) were analysed for retinoic acid using published methods for the extraction ${ }^{(26)}$ and HPLC ${ }^{(27)}$ procedures. In order to obtain detectable retinoic acid levels on HPLC, more tissue was homogenised $(0.6 \mathrm{~g})$ and a greater aliquot of the homogenate was used $(5 \mathrm{ml})$ for the extraction. Additionally, 3,4-didehydroretinol was added as the internal standard rather than acitretin and more ethanol $(10 \mathrm{ml})$ and hexane $(15 \mathrm{ml})$ were added to accommodate the larger homogenate. For the HPLC system, 50 out of $75 \mu \mathrm{l}$ redissolved extract was injected and chromatograms were generated at $350 \mathrm{~nm}$ to maximise detection of retinoic acid.

\section{Immunoblotting}

Liver samples $(0 \cdot 2-0.4 \mathrm{~g})$ were homogenised $(1: 3, \mathrm{w} / \mathrm{v})$ in a solution containing $1 \mathrm{mM}$-dithiothreitol, $1 \%$ Triton $\mathrm{X}-100$ and protease inhibitors including $1 \mathrm{mM}$-sodium orthovanadate, $2 \mu \mathrm{M}$-leupeptin, $2 \mu \mathrm{M}$-pepstatin, $5 \mu \mathrm{M}$-aprotinin and $400 \mu \mathrm{M}$ phenylmethylsulphonyl fluoride, $\mathrm{pH} 7 \cdot 4$. All of these reagents were purchased from Sigma Aldrich (St Louis, MO, USA) except aprotinin that was purchased from Calbiochem (San Diego, CA, USA). The cytosolic fraction from each homogenate was isolated using standard procedures. Gerbil liver cytosol $(60 \mu \mathrm{g}$ total protein) was initially separated by SDSPAGE and transferred to a Thermo Fisher Scientific Immobilon-P polyvinylidene difluoride membrane (Waltham, MA, USA). The membrane was blocked overnight at $4^{\circ} \mathrm{C}$ in a solution containing $6 \%$ non-fat dairy milk, $1 \%$ bovine serum albumin and $0.1 \%$ sodium azide, and washed in Tris-buffered saline multiple times. It was exposed to primary antibody (rabbit anti-mouse BCMO1, 1:1000 dilution or anti- $\alpha$-tubulin (Novus Biologicals, Littleton, CO, USA) 1:500 dilution) for $3 \mathrm{~h}$ at room temperature. Mouse liver cytosol was used as a positive control because the antibody was developed against mouse BCMO1. Blots were then washed in Tris-buffered saline and incubated for $1 \mathrm{~h}$ with horseradish peroxidase-conjugated goat anti-rabbit antibody. After washing, blots were treated with West Pico SuperSignal chemiluminescent substrate (Thermo Fisher Scientific). The BCMO1 blot was identified by its molecular weight $(65 \mathrm{kDa})$ and the appearance of a similar blot at that molecular weight in the mouse liver cytosol sample. Membranes were stripped using Restore $^{\mathrm{TM}}$ Western blot stripping buffer (Thermo Scientific, Rockford, IL, USA).

\section{Statistical analysis}

The Statistical Analysis System software, version 8.2 (SAS Institute, Inc., Cary, NC, USA; 2001) was used for data analyses. Values are presented as means and their standard deviations. Gerbil and liver weights, feed intakes, and serum and liver vitamin A concentrations were compared using ANOVA. When the main effect was significant, differences between the treatment groups were determined using Fisher's least significant difference test. Conversion factors for the vegetable diets were calculated by comparing the total liver retinol of the vegetable groups with that of the vitamin A 
Table 2. Macronutrient composition and carotenoid concentrations in four varieties of leafy vegetables used to prepare Mongolian gerbil feeds to determine vitamin A bioefficacy on a dry weight basis*

(Mean values and standard deviations)

\begin{tabular}{|c|c|c|c|c|c|c|c|c|}
\hline \multirow[b]{2}{*}{ Characteristic (local name) } & \multicolumn{2}{|c|}{$\begin{array}{l}\text { Solanun nigrum } \\
\text { (Morielle) }\end{array}$} & \multicolumn{2}{|c|}{$\begin{array}{l}\text { Moringa oliefera } \\
\text { (Moringa) }\end{array}$} & \multicolumn{2}{|c|}{$\begin{array}{l}\text { Vernonia calvoana } \\
\text { (Bitterleaf) }\end{array}$} & \multicolumn{2}{|c|}{$\begin{array}{c}\text { Hibiscus cannabinus } \\
\text { (Gabayidje) }\end{array}$} \\
\hline & Mean & SD & Mean & SD & Mean & SD & Mean & SD \\
\hline Protein $(\mathrm{g} / \mathrm{kg})$ & 246 & $21^{\mathrm{a}}$ & 258 & $16^{\mathrm{a}}$ & 207 & $19^{b}$ & 125 & $6^{\mathrm{c}}$ \\
\hline Carbohydrate (g/kg) & 535 & $18^{\mathrm{a}, \mathrm{b}}$ & 503 & $16^{\mathrm{b}}$ & 371 & $33^{c}$ & 587 & $45^{\mathrm{a}}$ \\
\hline Fibre $(\mathrm{g} / \mathrm{kg})$ & 66 & $6 \cdot 1^{d}$ & $92 \cdot 1$ & $7^{\mathrm{c}}$ & 289 & $36^{a}$ & 141 & $13^{\mathrm{b}}$ \\
\hline Lipids (g/kg) & 46 & $4^{\mathrm{c}}$ & 57 & $3^{\mathrm{b}}$ & 41 & $2^{c}$ & 84 & $8^{a}$ \\
\hline Energy (kJ/kg) & 14860 & $430^{\mathrm{b}}$ & 14850 & $1201^{b}$ & 15820 & $528^{b}$ & 17240 & $402^{a}$ \\
\hline Ash $(\mathrm{g} / \mathrm{kg})$ & 102 & $7^{a}$ & 92 & $6^{a}$ & 91 & $5^{a}$ & 66 & $4^{\mathrm{b}}$ \\
\hline$\beta$-Carotene (nmol/g) & 118 & $3.9^{\mathrm{a}}$ & 94 & $5 \cdot 7^{\mathrm{b}}$ & $18 \cdot 7$ & $2 \cdot 1^{c}$ & $82 \cdot 6$ & $5 \cdot 5^{\mathrm{b}}$ \\
\hline$\alpha$-Carotene $(\mathrm{nmol} / \mathrm{g})$ & 1.2 & 0.9 & ND & & ND & & ND & \\
\hline 13-cis- $\beta$-Carotene $(\mathrm{nmol} / \mathrm{g})$ & $20 \cdot 0$ & $1.8^{\mathrm{a}}$ & 17.5 & $2 \cdot 0^{a, b}$ & $7 \cdot 3$ & $0 \cdot 8^{\mathrm{c}}$ & $15 \cdot 1$ & $1.3^{\mathrm{b}}$ \\
\hline 9-cis- $\beta$-Carotene $(\mathrm{nmol} / \mathrm{g})$ & $30 \cdot 3$ & $2 \cdot 2^{\mathrm{a}}$ & $25 \cdot 2$ & $1.9^{\mathrm{b}}$ & 8.6 & $0.8^{\mathrm{c}}$ & 21.9 & $2 \cdot 2^{\mathrm{b}}$ \\
\hline$\beta$-Cryptoxanthin (nmol/g) & 1.2 & $0.0^{\mathrm{b}}$ & 0.7 & $0.0^{c}$ & ND & & 1.6 & $0.0^{\mathrm{a}}$ \\
\hline Total theoretical retinol $(\mathrm{nmol} / \mathrm{g}) \dagger$ & 348 & $21 \cdot 6^{\mathrm{a}}$ & 273 & $2.9^{b}$ & $69 \cdot 1$ & $4 \cdot 2^{d}$ & 239 & $24 \cdot 6^{c}$ \\
\hline
\end{tabular}

ND, not determined.

${ }^{*}$ Mean values within a row with a common letter were not significantly different $(P>0.05)$.

$\dagger$ Total theoretical retinol $=$ twice the sum of all isomeric forms of $\beta$-carotene $+\alpha$-carotene.

group corrected for the negative control group. $P<0.05$ was considered significant.

\section{Results \\ Composition of the leafy vegetables}

Protein levels of all the vegetable powders were between 125 and $258 \mathrm{~g} / \mathrm{kg}$ dry weight (Table 2). M. oleifera had the highest protein level and $H$. cannabinus had the lowest. The vegetables were rich sources of provitamin A carotenoids. $\beta$-Carotene was the predominant provitamin A carotenoid and the values for $S$. nigrum were higher than those of $M$. oleifera, $H$. cannabinus and $V$. calvoana. A similar relationship was also observed for the total theoretical retinol equivalents measured as twice the sum of all $\beta$-carotene isomers plus $\alpha$-carotene. The concentrations of the cis isomers of $\beta$-carotene in $V$. calvoana were also lower than in the other leafy vegetables, although this vegetable had a higher percentage of $c$ is isomers with respect to all-trans- $\beta$-carotene.

Feed intake, concentration of vitamin A in diets, body and liver weights

The daily feed intake (6.08 (SD 0.35) g) of the gerbils within the experimental periods did not differ and ranged from 5.65 (SD 0.22) $\mathrm{g}$ in the M. oleifera group to 6.46 (SD 1.05) $\mathrm{g}$ in the $V$. calvoana group. Feed intake was affected by day $(P<0.001)$, but there was no interaction of intake by day. The positive control group received 34.9 (SD 0.7) nmol retinyl acetate per day. The theoretical vitamin A of the vegetable groups did not differ and ranged from 33.0 (SD 1.6) nmol in the $M$. oleifera group to 37.2 (SD 5.1) nmol in the H. cannabinus group. The final body weights did not differ and ranged from 76.3 (SD 4.4) $\mathrm{g}$ in the baseline group to 78.5 (SD 5.9) $\mathrm{g}$ in the control group. Liver weights did not differ and ranged from 2.85 (SD 0.40) g in the $S$. nigrum group to $3 \cdot 10$ (SD 0.41) g in the H. cannabinus group.
Serum retinol, liver vitamin A concentrations, $\beta$-carotene 15,15'-monooxygenase-1 expression levels and conversion factors

Serum retinol concentrations ranged from 1.25 (SD 0.46) to 1.42 (SD 0.21 ) $\mu \mathrm{mol} / \mathrm{l}$ and did not differ among groups.

Liver vitamin A concentrations $(\mu \mathrm{mol} / \mathrm{g})$ and content ( $\mu \mathrm{mol} /$ liver) were affected by treatment $(P<0 \cdot 0001)$. The concentration and total vitamin A reserves (Fig. 1) were greater in the vitamin A supplement group than in the other groups $(P<0.05)$. Hepatic vitamin $\mathrm{A}$ in the negative control group was significantly lower than in the other groups due to continued vitamin A depletion during the treatment phase. No variation was observed among the vegetable groups for both the total liver vitamin A reserves and concentrations. Retinoic acid concentrations were highly variable, ranging

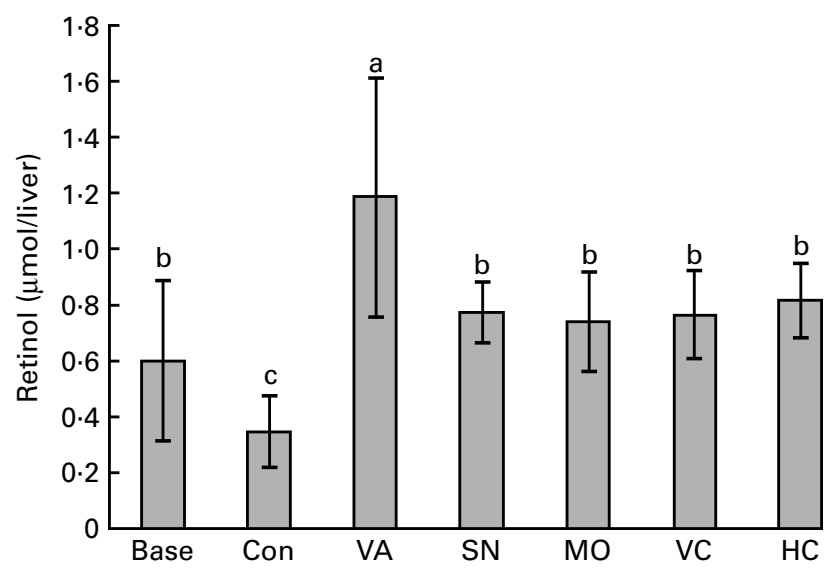

Fig. 1. Liver retinol reserves in $\mu \mathrm{mol} /$ liver of gerbils fed Solanum nigrum (SN), Moringa oleifera (MO), Vernonia calvoana (VC) or Hibiscus cannabinus (HC). A baseline (Base) group was killed before treatment started. A control (Con) group received cottonseed oil only and the vitamin A (VA) group received a dose of retinyl acetate that was matched to one-half (in mol) of the $\beta$-carotene equivalents ( $1 \mathrm{~mol} \beta$-carotene $+1 \mathrm{~mol}$ cis- $\beta$-carotenes $+1 / 2 \mathrm{~mol} \alpha$-carotene) that the vegetable groups consumed the day before. ${ }^{a, b, c}$ Mean values with a common letter were not significantly different. 


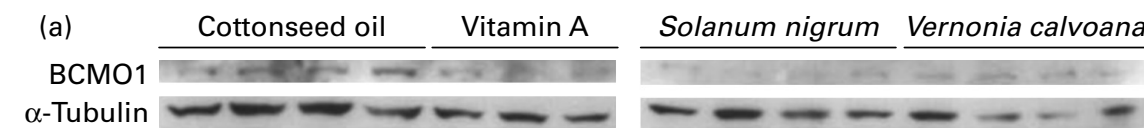

(b)

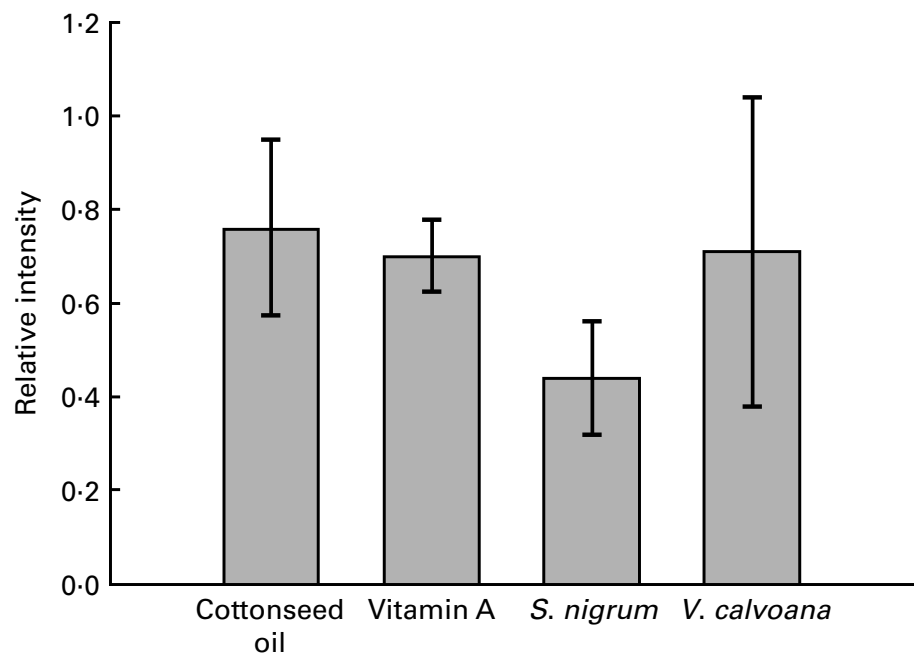

Fig. 2. Expression of $\beta$-carotene 15,15'-monooxygenase-1 (BCMO1) in the livers of gerbils fed a vitamin A-free basal diet and given daily oral doses of cottonseed oil only, vitamin A $(35 \mathrm{nmol})$, or fed a customised diet containing powdered Solanum nigrum or Vernonia calvoana containing $35 \mathrm{nmol}$ theoretical vitamin A (a). $\alpha$-Tubulin was used as a housekeeping protein. The BCMO1 bands were densitometrically analysed (b) with normalisation to $\alpha$-tubulin to measure expression level differences among treatment groups $(P=0 \cdot 12)$.

from 4.2 (SD 4.9) in the vitamin A group to 7.4 (SD 7.1) pmol/g liver in the $V$. calvoana group and did not differ among the groups $(P=0.77)$. Expression of BCMO1 was detected in the livers of animals from all analysed treatment groups (Fig. 2(a)). Densitometric analysis of the band intensity (Fig. 2(b)) did not reveal a main effect as determined by ANOVA $(P=0 \cdot 12)$.

The conversion factors were between 1.9 and $2.3 \mu \mathrm{g}$ $\beta$-carotene equivalents to $1 \mu \mathrm{g}$ retinol and were similar for all vegetable groups (Table 3 ). Therefore, the provitamin A carotenoid profile did not influence the bioconversion factor when fed at equal $\beta$-carotene equivalents.

\section{Discussion}

Leafy vegetables accompany most staple foods in the tropical regions of Africa. Knowledge of their nutritional value has greatly increased throughout the past decade ${ }^{(28-31)}$. Potential issues that affect the bioefficacy of provitamin A carotenoids from leafy vegetables have prompted diverse opinion as to their usefulness to alleviate vitamin A malnutrition in tropical
Africa. The present study was conducted to investigate the bioefficacy of these vegetables using Mongolian gerbils. The species of dark green tropical leafy vegetables used were chosen because they are rich in provitamin A carotenoids, especially $\beta$-carotene, and are readily available and widely consumed. The leaves are also common in many other developing countries. The percentage of the vegetables used in the diets of the present study was generally lower than the levels consumed naturally in association with staple foods in most African homes that have access to them.

The $\beta$-carotene concentrations in the leaves were between 18.7 and $118 \mathrm{nmol} / \mathrm{g}$ and were lower or higher than the results reported in previous studies on different leafy vegetables $^{(32-35)}$. These differences may be related to factors such as species, location, degree of maturity at harvest, cultivation and post-harvest handling practices ${ }^{(36)}$. The predominant provitamin A carotenoid in the vegetables was all-trans- $\beta$-carotene with small amounts of 9 -cis and 13-cis isomers. The percentage of cis isomer was higher in the $V$. calvoana than in the other vegetables. This may be attributed to the fact that $V$. calvoana was boiled and

Table 3. Bioconversion factors for tropical green leafy vegetables indigenous to Africa fed to Mongolian gerbils

\begin{tabular}{lcccc}
\hline & Vitamin A $(\mu \mathrm{mol} /$ /iver) & Control vitamin A $(\mu \mathrm{mol} /$ /iver) & Liver storage $(\mu \mathrm{mol})$ & Conversion factors $\mu \mathrm{g} \beta C E^{*}$ to $\mu \mathrm{g}$ retinol \\
\hline Solanum nigrum & 0.78 & 0.35 & 0.42 & 2.1 \\
Moringa oleifera & 0.74 & 0.35 & 0.39 & 2.3 \\
Vernonia calvoana & 0.77 & 0.35 & 0.42 & 2.1 \\
Hibiscus cannabinus & 0.81 & 0.35 & 0.47 & 1.9 \\
Vitamin A & 1.19 & 0.35 & 0.83 & 1 \\
\hline
\end{tabular}

${ }^{*} \beta C E$ are the $\beta$-carotene equivalents which were assumed to be equivalent to $1 \mathrm{~mol} \beta$-carotene +1 mol cis- $\beta$-carotenes $+1 / 2$ mol $\alpha$-carotene. The molecular weight of $\beta$-carotene is $537 \mathrm{~g} / \mathrm{mol}$ and that of retinol is $286 \mathrm{~g} / \mathrm{mol}$. In the final calculation, $0.94 \mu \mathrm{g} \beta C E$ yields $1 \mu \mathrm{g}$ retinol. 
squeeze-washed while the other vegetables were analysed raw. Processing increases the percentage of cis isomers in foods ${ }^{(37-39)}$.

Serum retinol concentrations did not differ, which agree with the fact that serum retinol is under homeostatic control and decreases only when liver stores have become deficient which is lower than $0.07 \mu \mathrm{mol} / \mathrm{g}^{(40)}$. The best measure of vitamin A status is liver stores ${ }^{(19)}$ because the liver is the primary storage site for vitamin $\mathrm{A}$ and permits the true calculation of the bioefficacy. Provitamin A carotenoids are converted to retinal, reduced to retinol and esterified to retinyl esters in the gut. After circulation in chylomicra and uptake by tissues, the excess vitamin A is stored in the liver or recirculated on retinol-binding protein. Storage of large amounts of vitamin $\mathrm{A}$ in the liver indicates adequate vitamin $\mathrm{A}$ status. The vitamin A depletion phase was not intended to initiate vitamin A deficiency but designed to deplete the adequate liver reserves. In the present study, the gerbils that ate the leafy vegetables had liver vitamin A that was significantly higher than the negative control group, while no significant differences were observed among the vegetable groups or between the vegetable groups and the baseline group. The vegetables maintained vitamin A status when fed at levels to meet daily needs. Gerbil liver retinoic acid concentrations were higher than those observed in postnatal rats ${ }^{(26)}$, but lower than those observed in prenatal monkeys ${ }^{(27)}$. The similar, but variable, levels of BCMO1 in the livers of gerbils from different treatment groups suggest that the liver expression of this enzyme is regulated by factors other than vitamin A status or the source of dietary vitamin A.

The conversion factors for the $\beta$-carotene in these vegetables to retinol were low indicating efficient bioconversion of the carotenoids to vitamin A from the different vegetables. These values are similar to values for $\beta$-carotene obtained from prior studies on maize and cassava using similar experimental conditions ${ }^{(23,25,41,42)}$. The bioconversion factors for maize and cassava were calculated based on $\beta$-carotene while that of the present study included $\alpha$-carotene in $S$. nigrum. Similar bioefficacy values were obtained in children from Indonesia with marginal vitamin A status using $\beta$-carotene supplements ${ }^{(43)}$. Much higher bioconversion factors were obtained by Dosti et al. ${ }^{(44)}$ for carotenoidrich carrots $(13-30: 1)$ and in this case, intake was between 5- and 25-fold higher with a reduced depletion period. Gerbils show similarity in provitamin A metabolism to man and therefore are an appropriate model for vitamin A bioefficacy studies $^{(45)}$.

Several human studies have proven that intake of leafy vegetables improves vitamin A status. Takyi ${ }^{(46)}$, who studied the effect of eating dark green leafy vegetables with added fat, found that Manihot sp. and Ceiba sp. leafy vegetables significantly enhanced the vitamin A status in children. In the same light, Tchum et al. ${ }^{(47)}$ showed that Ghanaian women fed African eggplant leaves had significant improvement in their vitamin A status over time. Jalal et al. ${ }^{(48)}$ studied factors that influence the success of using $\beta$-carotene as a vitamin A source in food-based programmes. They found that the incorporation of $\beta$-carotene (mainly in the form of red sweet potatoes) into meals significantly improved the vitamin A status of children. This was confirmed by van Jaarsveld et al. ${ }^{(49)}$ in South African school children using more sensitive indicators of vitamin A status. Despite these findings, bioavailability values for leafy vegetables have been reported to be low, i.e. $7 \%$ when compared with carrots $(19-30 \%)$ and broccoli $(22-24 \%)^{(50-53)}$. Thurnham ${ }^{(54)}$ reported that bioefficacy is greater when using small amounts of provitamin A carotenoids in subjects with low vitamin A status. This compares favourably with the results of the present study. The gerbils received milled vegetable powder while the human studies mostly used whole, cooked vegetables. Thus, the small particle size in the gerbil study may have also enhanced bioavailability. Other factors that may affect bioavailability and bioefficacy include the differences in methods used and the food matrix in which the provitamin A is located.

The present study clearly demonstrates that provitamin A carotenoids from these tropical leafy vegetables are bioefficacious because they contributed to vitamin A liver stores in Mongolian gerbils during depletion. Only small quantities of these vegetables are necessary to have an impact on vitamin A status and therefore not only staple foods should be promoted in the alleviation of vitamin A malnutrition. African countries can also rely on small quantities of inexpensive, locally available leafy vegetables for their vitamin A needs.

\section{Acknowledgements}

The authors do not have any conflicts of interest to declare. This research was partially supported by the American government through a Fulbright grant to R. A. E., Hatch Wisconsin Agricultural Experiment Station WIS04975 and NIH grant T32 DK007665 (J. T. D.). The work was conducted in the Tanumihardjo Laboratory of the Department of Nutritional Sciences, University of Wisconsin-Madison. R. A. E. applied for funding, prepared the vegetables and was responsible for the conduct of the study, data analysis and the drafting of the manuscript. J. T. D. developed the Western blot evaluation and analysed the data. J. P. M. performed the retinoic acid analyses and analysed the data. J. T. D. and J. P. M. added appropriate text to the manuscript. S. A. T. designed the study, oversaw the laboratory and revised the manuscript. The authors thank Christopher Davis, Sara Arscott, Rebecca Surles, Napaporn Riabroy, Rachel Novick, Roy Irving and Sangita Murali for their assistance in the laboratory work and animal care. The authors also thank Professor William Blaner for kindly providing BCMO1 antiserum.

\section{References}

1. Gibson RS \& Hotz C (2001) Dietary diversification/ modification strategies to enhance micronutrient content and bioavailability of diets in developing countries. $\mathrm{Br} J \mathrm{Nutr} \mathbf{8 5}$, S159-S166.

2. West KP Jr (2002) Extent of vitamin A deficiency among preschool children and women of reproductive age. J Nutr 132, 2857S-2866S.

3. McLauren DS \& Frigg M (2002) Sight and Life Manual. Practical Guide on Vitamin $A$ in Health and Disease, pp. 1-72. Basel: Sight and Life Publication.

4. World Health Organization (2009) Micronutrient deficiency. available at http://www.who.int/nutrition/topics/vad/en/index. html (accessed March 2009). 
5. Food and Agriculture Organization (1993) Preventing micronutrient deficiencies: food abundance and diversity are fundamental. Food Nutr Agric Bull 7, 8-17.

6. Mieko K \& Rodriguez-Amaya DB (2003) Carotenoid composition of hydroponic leafy vegetables. J Agric Food Chem 51, 2603-2607.

7. Heinonen MI, Ollilainen V, Linkola EK, et al. (1988) Carotenoids in Finnish foods: vegetables, fruits and berries. J Agric Food Chem 37, 655-659.

8. Mercadante AZ \& Rodriguez-Amaya DB (1991) Carotenoid composition of a leafy vegetable in relation to some agricultural variables. J Agric Food Chem 39, 1094-1097.

9. Muller H (1997) Determination of the carotenoid content in selected vegetables and fruit by HPLC and photodiode array detection. Z Lebensm Unters Forsch A 204, 88-94.

10. EL-Qudah JM (2009) Identification and quantification of major carotenoids in some vegetables. Am J Appl Sci 6, 492-497.

11. Tanumihardjo SA, Bouis H, Hotz C, et al. (2008) Biofortification of staple crops: an emerging strategy to combat hidden hunger. Comp Rev Food Sci Food Safety 7, 329-334.

12. Tanumihardjo SA (2008) Food-based approaches for ensuring adequate vitamin A nutrition. Comp Rev Food Sci Food Safety 7, 373-381.

13. Riedl J, Linseisen J, Hoffmann J, et al. (1999) Some dietary fibers reduce the absorption of carotenoids in women. $J$ Nutr 129, 2170-2176.

14. Brown MJ, Ferruzzi MG, Nguyen ML, et al. (2004) Carotenoid bioavailability is higher from salads ingested with full-fat than with fat-reduced salad dressings as measured with electrochemical detection. Am J Clin Nutr 80, 396-403.

15. Borel P (2003) Factors affecting intestinal absorption of highly lipophilic food microconstituents (fat-soluble vitamins, carotenoids and phytosterols). Chem Lab Med 41, 979-994.

16. Granado-Lorencio F, Olmedilla-Alonso B, Herrero-Barbudo C, et al. (2007) Comparative in vitro bioaccessibility of carotenoids from relevant contributors to carotenoid intake. J Agric Food Chem 55, 6387-6394.

17. Pasquier B, Armand M, Castelain C, et al. (1996) Emulsification and lipolysis of triacylglycerols are altered by viscous soluble dietary fibres in acidic gastric medium in vitro. Biochem $J$ 314, 269-275.

18. van Het Hof KH, West CE, Weststrate JA, et al. (2000) Dietary factors that affect the bioavailability of carotenoids. J Nutr 130, $503-506$

19. Lee CM, Lederman JD, Hofmann NE, et al. (1998) The Mongolian gerbil (Meriones unguiculatus) is an appropriate animal model for evaluation of the conversion of $\beta$-carotene to vitamin A. J Nutr 128, 280-286.

20. Tontisrin K, Nantel G \& Bhattacharjee L (2002) Food-based strategies to meet the challenges of micronutrient malnutrition in the developing world. Proc Nutr Soc 61, 243-245.

21. Reeves PG, Forrest HN \& Fahey GC Jr (1993) AIN 93 purified diets for laboratory rodents: final report of the American Institute of Nutrition ad hoc writing committee on the reformulation of the AIN76A rodent diet. $J$ Nutr 123, 939-951.

22. Association of Official Analytical Chemists (1997) Official Methods of Analysis, 16th ed. Washington, DC: AOAC.

23. Howe JA \& Tanumihardjo SA (2006) Carotenoid-biofortified maize maintains adequate vitamin A status in Mongolian gerbils. J Nutr 136, 2562-2567.

24. Valentine AR \& Tanumihardjo SA (2004) Adjustments to the modified relative dose response test for assessment of vitamin A status minimize the blood volume used in piglets. $J$ Nutr 134, 1186-1192.

25. Tanumihardjo SA \& Howe JA (2005) Twice the amount of $\alpha$-carotene isolated from carrots is as effective as $\beta$-carotene in maintaining the vitamin A status of Mongolian gerbils. J Nutr 135, 2622-2626.

26. Asson-Batres MA, Smith WB \& Clark G (2009) Retinoic acid is present in the postnatal rat olfactory organ and persists in vitamin A-depleted neural tissue. J Nutr 139, 1067-1072.

27. Mills JP, Terasawa E \& Tanumihardjo SA (2007) Excessive preformed vitamin A intake by mothers amplifies early fetal liver retinyl ester storage in captive Old World monkeys. Comp Med 57, 505-511.

28. Akwaowo EU, Ndon BA \& Etuk EU (2000) Minerals and antinutrients in fluted pumpkin (Telfairia occidentalis Hook F.). Food Chem 70, 235-240.

29. Antia BS, Akpan EJ, Okon PA, et al. (2006) Nutritive and anti-nutritive evaluation of sweet potatoes (Ipomoea batatas) leaves. Pak J Nutr 5, 166-168.

30. Ejoh RA, Djuikwo VN, Gouado I, et al. (2007) Effect of the method of processing and preservation on some quality parameters of three non-conventional leafy vegetables. Pak $J$ Nutr 6, 128-133.

31. Oduro I, Ellis WO \& Owusu D (2008) Nutritional potential of two leafy vegetables: Moringa oleifera and Ipomoea batatas leaves. Scient Res Essay 3, 57-60.

32. Bhaskarachary K, Rao DSS, Deosthale YG, et al. (1995) Carotene content of some common and less familiar foods of plant origin. Food Chem 54, 189-193.

33. Speek AJ, Speek-Saichua S \& Schreurs WHP (1988) Total carotenoid and $\beta$-carotene contents of Thai vegetables and the effect of processing. Food Chem 27, 245-257.

34. Tee E-S \& Lim C-L (1991) Carotenoid composition and content of Malaysian vegetables and fruits by the AOAC and HPLC methods. Food Chem 41, 309-339.

35. Ryan L, O'Connell O, O'Sullivan L, et al. (2008) Micellarisation of carotenoids from raw and cooked vegetables. Plant Foods Hum Nutr 63, 127-133.

36. Chen BH \& Chen YY (1992) Determination of carotenoids and chlorophylls in water convolvulus (Ipomea aquatica) by liquid chromatography. Food Chem 45, 129-134.

37. Aman R, Schieber A \& Carle R (2005) Effects of heating and illumination on trans-cis isomerization and degradation of $\beta$-carotene and lutein in isolated spinach chloroplasts. J Agric Food Chem 53, 9512-9518.

38. Rock CL, Lovalvo JL, Emenhiser C, et al. (1998) Bioavailability of $\beta$-carotene is lower in raw than processed carrots and spinach in women. J Nutr 128, 913-916.

39. Thakkar SK, Maziya-Dixon B, Dixon AGO, et al. (2007) Carotene micellarization during in vitro digestion and uptake by Caco- 2 cells is directly proportional to $\beta$-carotene content in different genotypes of cassava. J Nutr 137, 2229-2233.

40. Olson JA (1984) Serum levels of vitamin A and carotenoids as reflectors of nutritional status. J Natl Cancer Inst 73, 1439-1444.

41. Howe JA, Maziya-Dixon B \& Tanumihardjo SA (2009) Cassava with enhanced $\beta$-carotene maintains adequate vitamin A status in Mongolian gerbils (Meriones unguiculatus) despite substantial cis-isomer content. Br J Nutr 102, 342-349.

42. Davis C, Jing H, Howe JA, et al. (2008) $\beta$-Cryptoxanthin from supplements or carotenoid-enhanced maize maintains liver vitamin $\mathrm{A}$ in Mongolian gerbils (Meriones unguiculatus) better than or equal to $\beta$-carotene supplements. Br J Nutr 100, 786-793.

43. Van Lieshout M, West CE, Muhilal, et al. (2001) Bioefficacy of $\beta$-carotene dissolved in oil studied in children in Indonesia. Am J Clin Nutr 73, 949-958.

44. Dosti MP, Mills JP, Simon PW, et al. (2006) Bioavailability of $\beta$-carotene $(\beta C)$ from purple carrots is the same as typical orange carrots while high $\beta C$ carrots increase $\beta C$ stores in Mongolian gerbils (Meriones unguiculatus). Br J Nutr 96, $258-267$. 
45. Pollack J, Campbell JM, Potter SM, et al. (1994) Mongolian gerbils (Meriones unguiculatus) absorb beta-carotene intact from a test meal. $J$ Nutr 124, 869-873.

46. Takyi EEK (1999) Children's consumption of dark green, leafy vegetables with added fat enhances serum retinol. J Nutr 129, $1549-1554$.

47. Tchum SK, Newton S, Tanumihardjo SA, et al. (2009) Evaluation of a green leafy vegetable intervention in Ghanaian postpartum mothers. Afr J Food Agric Nutr Develop 9, 1294-1308.

48. Jalal F, Nesheim MC, Agus Z, et al. (1998) Serum retinol concentrations are affected by food sources of $\beta$-carotene, fat intake, and anthelmintic drug treatment. Am J Clin Nutr 68, $623-629$.

49. van Jaarsveld PJ, Faber M, Tanumihardjo SA, et al. (2005) $\beta$-carotene-rich orange-fleshed sweet potato improves the vitamin A status of primary school children assessed with the modified-relative-dose-response test. Am J Clin Nutr $\mathbf{8 1}$ 1080-1087.

50. De Pee S, West CE, Muhilal, et al. (1995) Lack of improvement in vitamin A status with increased consumption of dark-green leafy vegetables. Lancet 346, 75-81.

51. Brown ED, Micozzi MS, Craft NE, et al. (1989) Plasma carotenoids in normal men after a single ingestion of vegetables or purified $\beta$-carotene. Am J Clin Nutr 49, 1258-1265.

52. Micozzi MS, Brown ED, Edwards BK, et al. (1992) Plasma carotenoid response to chronic intake of selected foods and $\beta$-carotene supplements in men. Am J Clin Nutr 55, 1120-1125.

53. Törrönen R, Lehmusaho M, Häkkinen S, et al. (1996) Serum $\beta$-carotene response to supplementation with raw carrots, carrot juice or purified $\beta$-carotene in healthy non-smoking women. Nutr Res 16, 565-575.

54. Thurnham DI (2007) Bioequivalence of $\beta$-carotene and retinol. J Sci Food Agric 87, 13-39. 